\title{
Synthesis and characterization of highly branched polymethacrylates via self-condensing oxyanionic copolymerization
}

\author{
Zhifeng Jia *, Wei Huang, Deyue Yan *
}

College of Chemistry and Chemical Engineering, Shanghai Jiao Tong University, 800 Dongchuan Road, Shanghai 200240, People's Republic of China;

Fax +86-21-54741297; jiazhifeng@sjtu.edu.cn, dyyan@sjtu.edu.cn

(Received: October 4, 2004; published: March 12, 2005)

\begin{abstract}
Highly branched polymethacrylates were successfully synthesized by the self-condensing vinyl copolymerization of 2-dimethylaminoethyl methacrylate (DMAEMA) and methacrylic inimer containing a vinyl group and an oxyanionic active site, which was formed via the in situ reaction of 2-hydroxyethyl methacrylate (HEMA) with potassium hydride. Depending on the comonomer ratio, $\mathrm{Y}=$ $[\text { DMAEMA }]_{0} /[\mathrm{HEMA}]_{0}$, branched poly(DMAEMA)s with number-average molecular weights between 4800 and 22000 and degree of branching between 0.09 and 0.38 were obtained, as evidenced by gel permeation chromatography and NMR analysis. Thermally reversible phase transitions were observed for the branched poly(DMAEMA)s produced at higher comonomer ratio $(y \geq 5)$. Quaternization of the branched poly(DMAEMA)s with methyl iodide led to cationic polyelectrolytes with branched structure.
\end{abstract}

\section{Introduction}

Highly branched polymers, dendrimers and hyperbranched polymers are of considerable scientific and industrial interest due to their unique shapes and properties [1-3]. Dendrimers are synthesized by multistep reaction procedures, whereas hyperbranched polymers are usually prepared by one-step polymerization of $A B_{x}$ type monomers. Therefore, hyperbranched polymers are suitable for large-scale production and a wide range of applications.

In 1995, Fréchet et al. [4] developed a novel approach to hyperbranched polymers, which was coined as self-condensing vinyl polymerization (SCVP). In SCVP an inimer (initiator-monomer) [5] with the general structure $A B^{*}$ is used, where $A$ stands for a double bond and $\mathrm{B}^{*}$ is an initiating site. Later this technique was developed to prepare highly branched copolymers by self-condensing vinyl copolymerization (SCVCP) of $A B^{*}$ inimers with conventional monomers. It has been shown theoretically $[6,7]$ and experimentally [8-18] that the molecular weights and the degree of branching of the obtained copolymers can be controlled by the comonomer ratio in SCVCP. Depending on the chemical nature of the comonomer, functional groups can be incorporated into the copolymer. Some highly branched polyelectrolytes $[10,11]$ and liquid-crystalline copolymers [12] have been prepared by SCVCP. 
Recently, Nagasaki et al. [19,20] reported that potassium ethoxide can initiate the anionic vinyl polymerization of 2-(tert-butyldimethylsiloxy)ethyl methacrylate and 2diethylaminoethyl methacrylate in tetrahydrofuran (THF) at room temperature. This novel approach was defined as oxyanionic polymerization. Armes et al. [21,22] have performed the oxyanionic polymerization of other tertiary amine methacrylate monomers, viz., DMAEMA and 2-( $N$-morpholino)ethyl methacrylate. The oxyanionic polymerization has been used to prepare hyperbranched polymers via ring-opening polymerization [23-25]. In a recent publication, we described the oxyanionic polymerization of HEMA to synthesize hyperbranched polymers via SCVP [26].

In recent years, branched polyelectrolytes have attracted considerable attention [27-28]. Müller et al. have described the synthesis of highly branched polyelectrolytes based on poly(methacrylic acid) [10] and poly(2-diethylaminoethyl methacrylate) [11] by SCVCP via ATRP. However, these branched copolymers prepared at low comonomer ratio are insoluble in water due to the high fraction of nonpolar inimer segments in the copolymers. In this work, we report the synthesis of highly branched cationic polyelectrolytes by SCVCP of the methacrylic $A B^{*}$ inimer precursor HEMA with DMAEMA via oxyanionic polymerization, followed by quaternization. Both HEMA and DMAEMA are polar monomers, and the prepared copolymers and polyelectrolytes can be easily soluble in water at room temperature.

\section{Results and discussion}

\section{Synthesis}

The monomer HEMA, containing a polymerizable vinyl group and a hydroxyl group, represents a latent inimer $\left(\mathrm{AB}^{*}\right)$. The hydroxyl groups of HEMA can be stimulated to be initiating centres (oxyanions) by potassium hydride; thus HEMA becomes a sort of inimer with a vinyl group and an active site (Scheme 1). We have demonstrated the self-condensing oxyanionic polymerization of HEMA results in hyperbranched polymers [26]. In this paper, we describe the preparation of hyperbranched copolymers from the commercially available monomers HEMA and DMAEMA by self-condensing oxyanionic polymerization. The synthetic route to the branched copolymers is outlined in Scheme 1. The curved lines represent polymer chains. $A^{*}, B^{*}$ and $M^{*}$ are the active units, whereas $a, b$, and $m$ are the reacted ones. After the polymerization system is quenched by methanol, $A^{*}, B^{*}$ and $M^{*}$ are transferred to $A H, B H$ and $M H$ (see Scheme 1).

In the polymerization process, HEMA first reacts with an equivalent amount of $\mathrm{KH}$ in order to form the inimer and then DMAEMA is added. The polymerization is conducted at $0^{\circ} \mathrm{C}$ at different comonomer ratios, $\gamma=[\mathrm{DMAEMA}]_{0} /[\mathrm{HEMA}]_{0}$ between 1 and 20. The molecular weights and molecular weight distributions of the copolymers were determined by conventional gel permeation chromatography (GPC) using polystyrene standards. The results are given in Tab. 1. For $y=1$, a product (P1) with lower molecular weight was obtained when $\mathrm{KH}$ was used alone. Obviously, the solubility of living species in the reaction medium restricts the molecular weight. A high molecular weight product was obtained when 18-crown- 6 was added to enhance the solubility of living species (Tab. 1, P2-P3). All samples showed a relatively narrow molecular weight distribution. The number-average molecular weights of the copolymers, $M_{\mathrm{n}}$, increased with increasing comonomer ratio, $\mathrm{Y}$ (Tab. 1, P1, P4 - P6). 


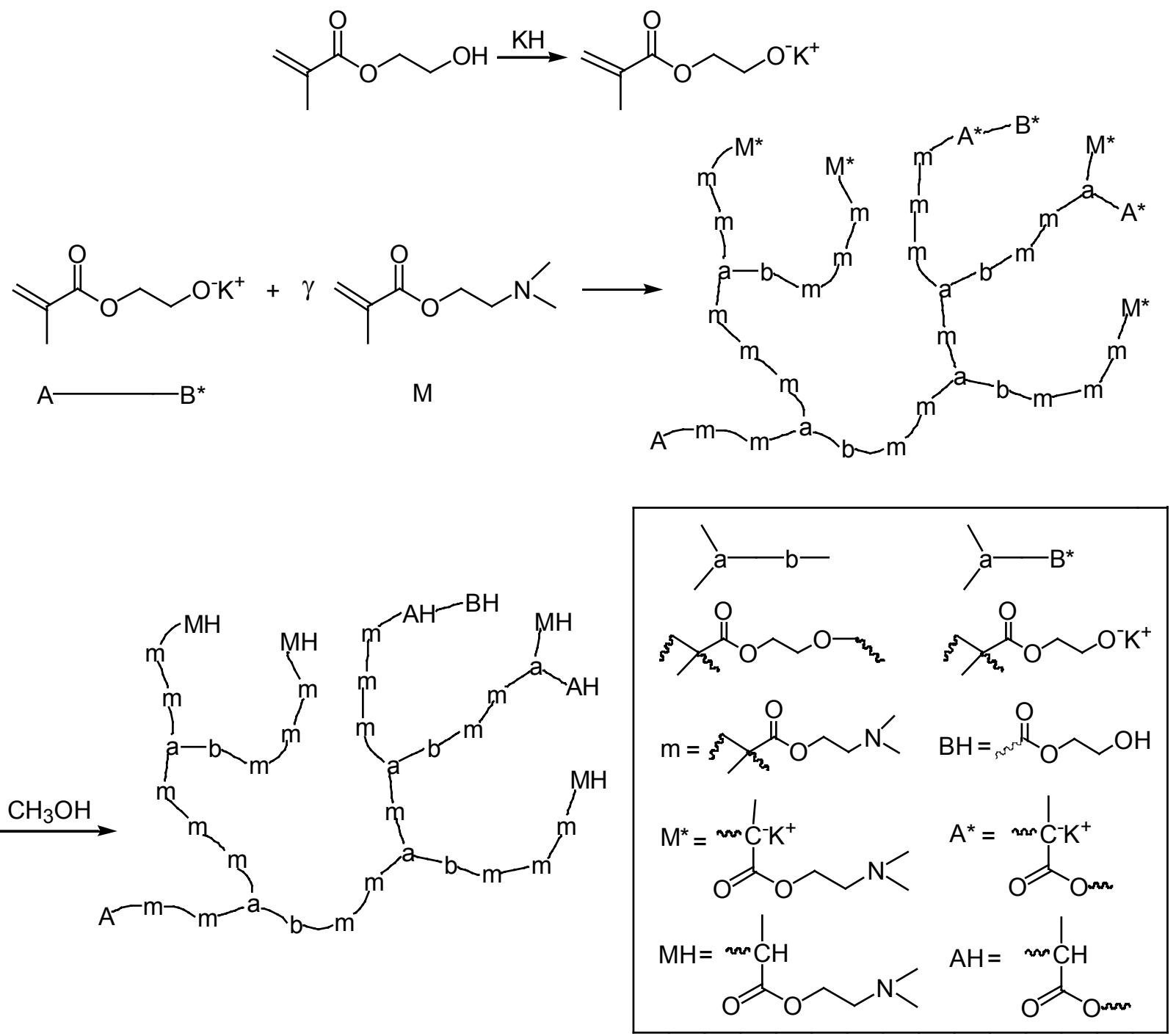

Scheme 1. Synthesis of branched polymethacrylates via SCVCP

Tab. 1. SCVCP results of HEMA and DMAEMA at different comonomer ratios

\begin{tabular}{|c|c|c|c|c|c|c|c|}
\hline \multirow[t]{2}{*}{ Entry $V^{c)}$} & $\begin{array}{l}\text { Yield } \\
\text { in \% }\end{array}$ & $\begin{array}{l}M_{\mathrm{n}}^{\mathrm{d})} \\
(\mathrm{GPC})\end{array}$ & $M_{\mathrm{d}} / M_{\mathrm{n}}$ & $\begin{array}{l}\left.M_{\mathrm{n}}{ }^{\mathrm{e}}\right) \\
(\mathrm{NMR})\end{array}$ & $D^{2} B_{N M R}{ }^{f)}$ & $\begin{array}{l}\text { DMAEMA fraction in } \\
\text { the polymer }\end{array}$ & $\begin{array}{l}\text { LCST } \\
\text { in }{ }^{\circ} \mathrm{C}\end{array}$ \\
\hline & & & & & & calc. $^{\text {g) }}$ obs. (NMR) & \\
\hline
\end{tabular}

\begin{tabular}{|c|c|c|c|c|c|c|c|c|c|}
\hline $\mathrm{P} 1^{\text {a) }}$ & 1 & 29 & 4800 & 1.85 & 3400 & n.d. & 0.50 & 0.47 & - \\
\hline$P 2^{b)}$ & 1 & 66 & 13100 & 1.62 & 11000 & 0.38 & 0.50 & 0.48 & - \\
\hline$P 3^{b)}$ & 3 & 71 & 22500 & 1.47 & & 0.21 & 0.75 & 0.79 & - \\
\hline P4 ${ }^{\text {a) }}$ & 5 & 79 & 15500 & 1.46 & 9200 & 0.17 & 0.83 & 0.81 & 28.7 \\
\hline P5 ${ }^{\text {a) }}$ & 10 & 81 & 16500 & 1.49 & 13400 & 0.09 & 0.91 & 0.89 & 37.2 \\
\hline$P 6^{\text {a) }}$ & 20 & 82 & 19000 & 1.38 & 15800 & . & 0.95 & 0.94 & 42.0 \\
\hline
\end{tabular}

a) Initiated by $\mathrm{KH} .{ }^{\text {b) }}$ Initiated by $\mathrm{KH} /$ crown. ${ }^{\mathrm{c})} \mathrm{Y}=[\mathrm{DMAEMA}]_{0} /[\mathrm{HEMA}]_{0}$. ${ }^{\text {d) }}$ Determined by GPC. ${ }^{e)}$ Calculated from the integrated intensity of the ${ }^{1} \mathrm{H}$ NMR spectrum. For P3, no signals of double bonds could be detected. ${ }^{\text {f) }}$ Determined by ${ }^{1} \mathrm{H}$ NMR using Eq. (2). "9) Calculated from the composition in the feed. 
The same tendency was also observed in other SCVCPs [8,10-13]. It is already known that GPC calibrated with linear polymers hardly gives quantitative molecular weights since the hydrodynamic volume of branched polymers is different from that of linear analogues. GPC-MALLS (multi-angle laser light scattering) using THF as eluent was performed to determine the absolute molecular weights of the branched poly(DMAEMA)s. Unfortunately, no reliable molecular weights could be obtained because no refractive index increment $(\mathrm{d} n / \mathrm{d} c)$ was detected. This is believed to be due to the adsorption of DMAEMA on the GPC columns, a phenomenon previously reported [29].

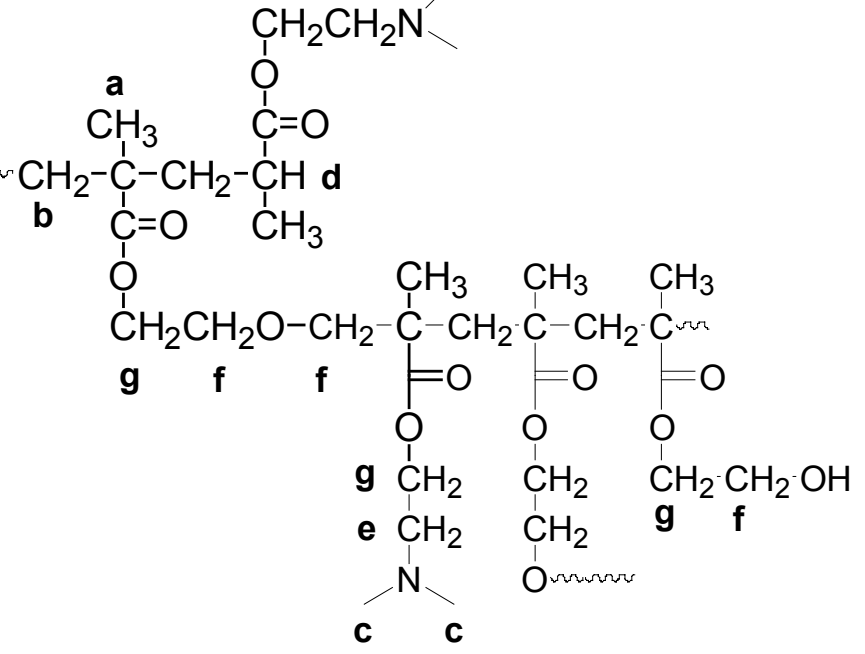

(a)

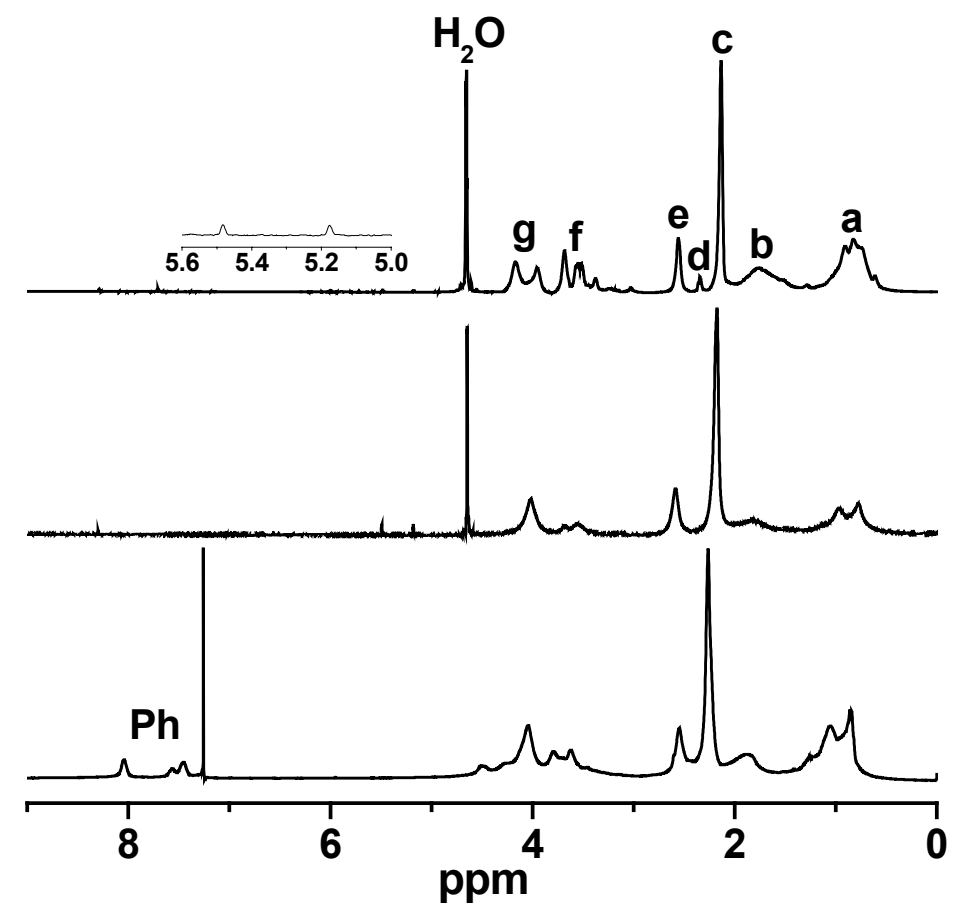

Fig. 1. ${ }^{1} \mathrm{H}$ NMR spectra of the copolymers: a) P2; b) P4; c) benzoylated sample of P2

Provided that there is no side reaction, each macromolecule should have one double bond. The molecular weight can be calculated by comparison of the intensities of the ${ }^{1} \mathrm{H}$ NMR signals of double bond and methyl group (Fig. 1). The results are listed in 
Tab. 1. The molecular weight determined by GPC was larger than that determined by NMR. A probable explanation is the formation of aggregates between polymers.

\section{Degree of branching}

The structure of the branched poly(DMAEMA)s was confirmed by ${ }^{1} \mathrm{H}$ NMR spectroscopy. Fig. $1 \mathrm{a}$ and $\mathrm{b}$ show the typical ${ }^{1} \mathrm{H}$ NMR spectra of copolymers prepared using different comonomer ratios. The signals from 5.0 to $6.0 \mathrm{ppm}$ are assigned to the protons of the double bond at the end of the copolymers. The peaks $\mathbf{g}$ from 3.9 to 4.2 ppm correspond to the methylene protons adjacent to the ester oxygen in DMAEMA and HEMA units. The signals $\mathrm{f}$ from 3.4 to $3.8 \mathrm{ppm}$ are assigned to the methylene protons, $-\mathrm{COO}-\mathrm{CH}_{2}-\mathrm{CH}_{2}-\mathrm{OH}$ and $-\mathrm{COO}-\mathrm{CH}_{2}-\mathrm{CH}_{2}-\mathrm{O}-\mathrm{CH}_{2}-$. The latter protons are assigned to $b$, which is formed by the activation of $\mathrm{B}^{*}$ and subsequent addition of monomer. The peaks e from 2.5 to $2.7 \mathrm{ppm}$ and $\mathbf{c}$ from 2.0 to $2.2 \mathrm{ppm}$ correspond to the methylene and methyl protons adjacent to a nitrogen atom in the DMAEMA unit, respectively. The peaks $\mathrm{d}$ from 2.3 to $2.4 \mathrm{ppm}$ are assigned to the methine protons, which resulted from $\mathrm{MH}$ and $\mathrm{AH}$. The peaks $\mathbf{b}$ in the range of 1.5 to $2.0 \mathrm{ppm}$ ascribe to the methylene protons of the copolymer backbones. Peaks a from 0.6 to $1.1 \mathrm{ppm}$ originate from the methyl group. The ${ }^{1} \mathrm{H}$ NMR spectra definitely confirm the presence of a hyperbranched structure.

The DMAEMA content in the copolymers can be calculated from the integration ratio of signals at $2.5-2.7 \mathrm{ppm}$ due to the methylene protons adjacent to a nitrogen atom in the DMAEMA segment and the methyl protons of the backbone. The comonomer content determined by ${ }^{1} \mathrm{H}$ NMR is in good agreement with the comonomer composition in the feed, which corresponds to the $y$ ratio, as can be seen in Tab. 1.

For equal reactivity of the active sites, the degree of branching determined by NMR $\left(\mathrm{DB}_{\mathrm{NMR}}\right)$ at full conversion can be calculated according to the following equation [8]:

$$
\mathrm{DB}_{\mathrm{NMR}}=2\left(\frac{b}{\gamma+1}\right)\left[1-\left(\frac{b}{\gamma+1}\right)\right]
$$

However, we cannot calculate the proportion of $b$ from the ${ }^{1} \mathrm{H}$ NMR spectra because its signals overlap with the $B^{*}$ signals $(3.4-3.8 \mathrm{ppm})$. As implied in Scheme 1 , $B^{*}$ $\left(-\mathrm{O}^{-} \mathrm{K}^{+}\right)$was transformed to hydroxyl groups after it was terminated by methanol. The hydroxyl groups can be benzoylated with benzoyl chloride, and the ratio $B^{*} /\left(\gamma^{+1}\right)$ can be determined by comparing the integration of benzyl protons to that of the methyl protons in the ${ }^{1} \mathrm{H}$ NMR spectra of the benzoylated copolymers (Fig. 1c). Because of $b$ $=1-B^{*}, \mathrm{DB}_{\mathrm{NMR}}$ can be calculated from Eq. (2).

$$
\mathrm{DB}_{\mathrm{NMR}}=2\left(\frac{1-B^{*}}{\gamma+1}\right)\left[1-\left(\frac{1-B^{*}}{\gamma+1}\right)\right]
$$

The calculated results are listed in Tab. 1. In this copolymerization system, there are differences in the rate constants of the oxyanionic and the carbanionic propagating centres. Therefore, $\mathrm{DB}_{\mathrm{NMR}}$ should be regarded as an approximation.

\section{Thermal sensitivity}

The DMAEMA homopolymer exhibits an inverse temperature solubility behaviour and its lower critical solution temperature (LCST) lies between 33 and $47^{\circ} \mathrm{C}$ at $\mathrm{pH} 7$, depending on the molecular weight [30]. The temperature-responsive behaviour of 
the branched copolymers was studied. To obtain the LCSTs, transmittances of aqueous solutions containing $1 \%(\mathrm{w} / \mathrm{w})$ copolymer were measured using UV-visible spectrometer at $500 \mathrm{~nm}$. Fig. 2 shows the transmittance-temperature curve of the copolymers prepared at different comonomer ratios. The LCSTs were determined as the temperature corresponding to $10 \%$ reduction in the original transmittance. The LCST values of the copolymers are given in Tab. 1. The content of HEMA in the copolymer affects the thermal sensitivity of the copolymers. The LCSTs were shifted to lower temperature with increasing HEMA content in the copolymers. Otherwise, the thermoreversibility of the copolymers is weakened and disappeared as the content of HEMA in the copolymers was increased (Fig. 2). For P5 and P6, there was a sharp decrease in transmittance when the phase transition was achieved. The transmittance of $\mathrm{P} 4$ decreased slowly over a wide temperature range between 28 and $37^{\circ} \mathrm{C}$, indicating the weaker thermal sensitivity of the copolymers. The thermoreversibility was not found for the copolymers of higher content of HEMA (P1 - P3). This may be attributed to the fact that the higher the HEMA content, the fewer the amido groups in the copolymers. This is consistent with the phenomenon reported for $\mathrm{N}$-isopropylacrylamide-co-hydroxyethyl methacrylate copolymeric hydrogels [31].

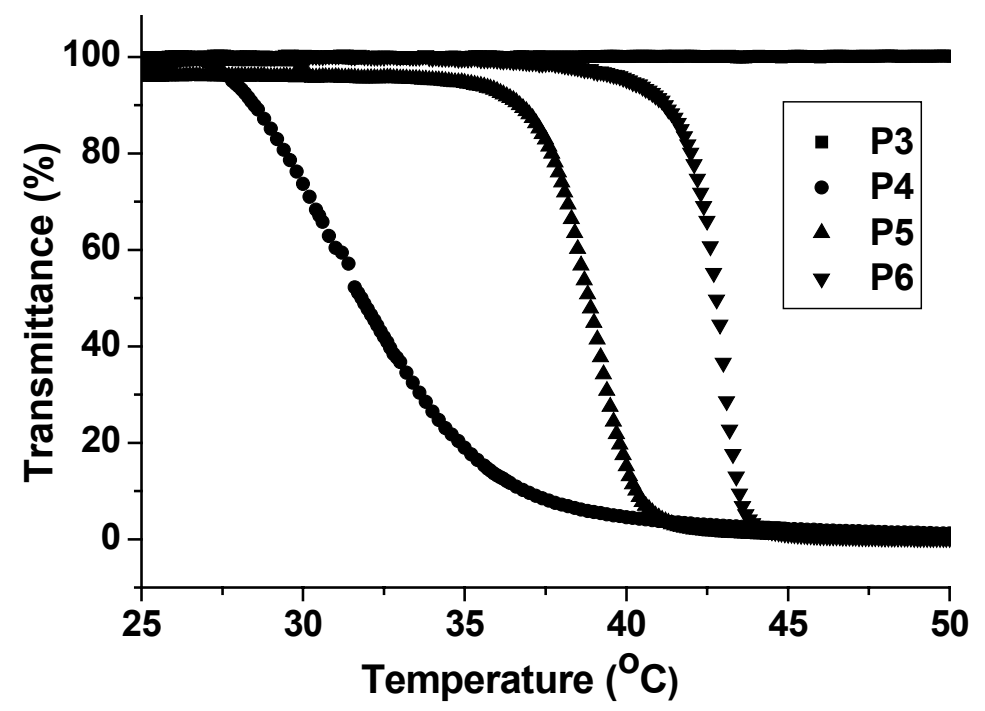

Fig. 2. Effect of temperature on the transmittance of aqueous solutions of the branched copolymers

\section{Quaternization of branched poly(DMAEMA)s}

The quaternization reaction was carried out using 2-fold molar excess of $\mathrm{CH}_{3}$ l compared to DMAEMA units at room temperature. The extent of quaternization was assessed by ${ }^{1} \mathrm{H}$ NMR spectroscopy. Fig. 3 shows ${ }^{1} \mathrm{H}$ NMR spectra of branched poly(DMAEMA)s and their quaternized products. Peak $C$ at $2.2 \mathrm{ppm}$ represents the six dimethylamino protons. After quaternization of the branched poly(DMAEMA)s with iodomethane, nine quaternary ammonium protons appear at $3.2 \mathrm{ppm}$. Peaks $A$ and $B$ shifted downfield from 4.0 and $2.6 \mathrm{ppm}$ to 4.5 and $3.8 \mathrm{ppm}$, respectively. The degree of quaternization was determined to be $c .100 \%$ by comparison of the integrals of peaks C' and B'. The absence of any unquaternized dimethylamino protons at 2.1 $2.4 \mathrm{ppm}$ in Fig. 3b confirms this calculation. This observation is in good agreement with the result reported by Armes et al. [32]. All the branched poly(DMAEMA)s and quaternized poly(DMAEMA)s are easily soluble in water at room temperature. 


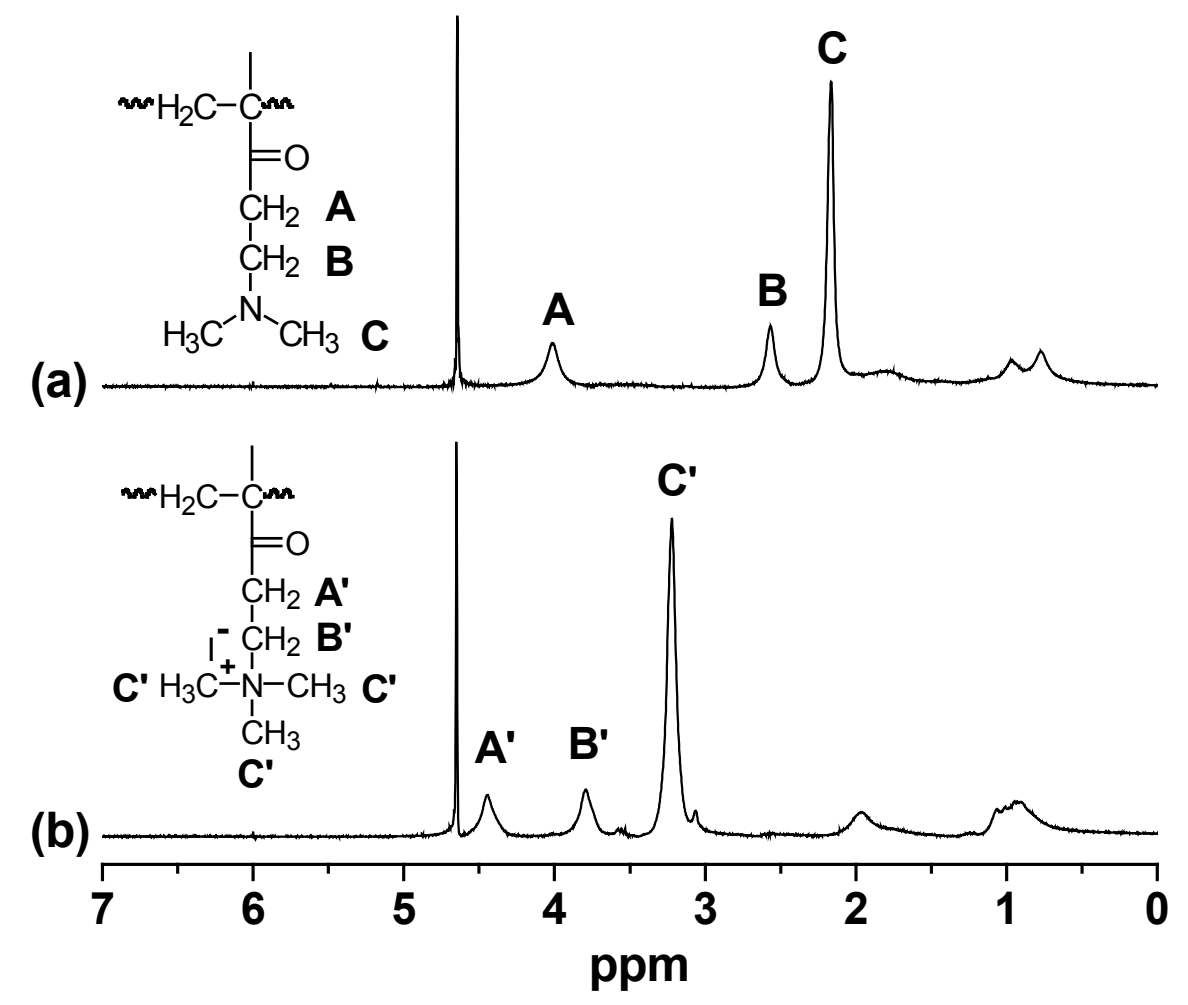

Fig. 3. ${ }^{1} \mathrm{H}$ NMR spectra of P5: a) before quaternization, and b) after quaternization with $\mathrm{CH}_{3} \mathrm{l}$

\section{Experimental part}

\section{Materials}

2-Hydroxyethyl methacrylate (HEMA), 18-crown-6 and potassium hydride $(\mathrm{KH}, 35 \%$, dispersion in mineral oil) were purchased from Aldrich Chemical Co. Inc. HEMA was purified according to ref. [33]. 2-Dimethylaminoethyl methacrylate (DMAEMA, Acros) was dried over calcium hydride $\left(\mathrm{CaH}_{2}\right)$ and distilled under reduced pressure. 18Crown-6 was recrystallized from acetonitrile. Methyl iodide was purchased from Shanghai Reagent Company and used as received. Tetrahydrofuran (THF) was purified by refluxing over fresh sodium-benzophenone complex (a deep purple colour indicating an oxygen- and moisture-free solvent) and distilled before used.

\section{Characterization}

NMR measurements were recorded with a Varian MERCURY plus- $400 \mathrm{MHz}$ spectrometer using $\mathrm{D}_{2} \mathrm{O}$ as the solvent. Molecular weight and molecular weight distribution were determined by gel permeation chromatography (GPC) on a Perkin-Elmer series 200 system ( $10 \mu \mathrm{m}$ PL gel, $300 \times 7.5 \mathrm{~mm}$ mixed-B columns, polystyrene calibration) equipped with a refractive index (RI) detector. Dimethylformamide containing 0.01 $\mathrm{mol} / \mathrm{L}$ lithium bromide was used as the mobile phase at a flow rate of $1 \mathrm{~mL} / \mathrm{min}$ at $40^{\circ} \mathrm{C}$. LCSTs of the copolymer solutions $(1 \%)$ were measured by monitoring the transmittance of a $500 \mathrm{~nm}$ light beam using a Cintra 10e UV-visible spectrometer. The temperature of the solution was increased from 25 to $60^{\circ} \mathrm{C}$ at a rate of $1.0^{\circ} \mathrm{C} / \mathrm{min}$. 


\section{Synthesis of branched copolymers}

A typical polymerization procedure was as follows (P2): A suspension of $\mathrm{KH}$ in mineral oil (35 wt.- $\%$ ) was introduced in a dry pre-weighed $50 \mathrm{~mL}$ Schlenk flask under argon atmosphere. The mineral oil was removed by three times extraction with THF added to the flask by syringe. The remaining THF was removed in vacuum. When $\mathrm{KH}$ was dried, the flask was weighed to determine the amount of $\mathrm{KH}(0.256 \mathrm{~g}, 6.38$ $\mathrm{mmol}) .30 \mathrm{~mL}$ fresh THF solution of 18 -crown-6 $(1.689 \mathrm{~g}, 6.39 \mathrm{mmol})$ was added and the flask was cooled to $0^{\circ} \mathrm{C}$. Then HEMA $(0.836 \mathrm{~g}, 6.41 \mathrm{mmol})$ and DMAEMA $(1.010$ $\mathrm{g}, 6.42 \mathrm{mmol}$ ) were added in sequence. The polymerization was conducted at $0^{\circ} \mathrm{C}$ for $12 \mathrm{~h}$ and terminated with degassed methanol. The product was neutralized by filtration over the cation-exchange resin. The obtained copolymer was precipitated twice from methanol solution into diethyl ether and dried in vacuum for $24 \mathrm{~h}$ at $50^{\circ} \mathrm{C}$.

${ }^{1} \mathrm{H}$ NMR $\left(\mathrm{D}_{2} \mathrm{O}\right)$ : 0.6 - 1.1 (- $\left.\mathrm{CH}_{2}-\mathrm{C}\left(\mathrm{CH}_{3}\right)-\mathrm{COO}-,-\mathrm{CH}_{2}-\mathrm{CH}\left(\mathrm{CH}_{3}\right)-\mathrm{COO}-\right), 1.5$ - 2.0 (- $\mathrm{CH}_{2}-$ $\left.\mathrm{C}\left(\mathrm{CH}_{3}\right)-\mathrm{COO}-\right), 2.0$ - 2.2 (-N $\left.\left(\mathrm{CH}_{3}\right)_{2}\right), 2.3$ - $2.4\left(-\mathrm{CH}_{2}-\mathrm{CH}\left(\mathrm{CH}_{3}\right)-\mathrm{COO}-\right), 2.5$ - 2.7 (-COO$\left.\mathrm{CH}_{2}-\mathrm{CH}_{2}-\mathrm{N}\left(\mathrm{CH}_{3}\right)_{2}\right), 3.4$ - $3.8\left(-\mathrm{COO}^{-} \mathrm{CH}_{2}-\mathrm{CH}_{2}-\mathrm{O}-\mathrm{CH}_{2-},-\mathrm{COO}-\mathrm{CH}_{2}-\mathrm{CH}_{2}-\mathrm{OH}\right), 3.9$ - 4.2 $\left(-\mathrm{COO}-\mathrm{CH}_{2}-\mathrm{CH}_{2-}^{-}\right.$.

\section{End-capping reaction}

A typical end-capping reaction procedure was as follows: To a mixture of copolymer P2 $(0.51 \mathrm{~g})$, triethylamine $(5 \mathrm{~mL})$ and chloroform $(5 \mathrm{~mL})$, benzoyl chloride $(0.6 \mathrm{~mL})$ was added. The reaction mixture was stirred at room temperature for $24 \mathrm{~h}$ under argon atmosphere. A saturated $\mathrm{NaHCO}_{3}$ solution $(50 \mathrm{~mL})$ was added to the mixture. Then the solution was poured into a funnel and the organic layer was separated. The aqueous layer was extracted three times with $50 \mathrm{~mL} \mathrm{CHCl}$. The combined organic layer was dried over anhydrous $\mathrm{MgSO}_{4}$. After filtration, the mixture was concentrated under reduced pressure and precipitated into hexane to give end-capped copolymer.

${ }^{1} \mathrm{H}$ NMR $\left(\mathrm{CDCl}_{3}\right): 0.8$ - $1.2\left(-\mathrm{CH}_{2}-\mathrm{C}\left(\mathrm{CH}_{3}\right)-\mathrm{COO}-,\right), 1.6$ - $2.0\left(-\mathrm{CH}_{2}-\mathrm{C}\left(\mathrm{CH}_{3}\right)-\mathrm{COO}-\right), 2.0-$ $2.2\left(-\mathrm{N}\left(\mathrm{CH}_{3}\right)_{2}\right), 2.4-2.6\left(-\mathrm{COO}-\mathrm{CH}_{2}-\mathrm{CH}_{2}-\mathrm{N}\left(\mathrm{CH}_{3}\right)_{2}\right), 3.5-3.8\left(-\mathrm{COO}-\mathrm{CH}_{2}-\mathrm{CH}_{2}-\mathrm{O}-\right.$ $\left.\mathrm{CH}_{2}-\right), 3.9$ - 4.2 (-COO- $\left.\mathrm{CH}_{2}-\mathrm{CH}_{2}-\right), 4.2$ - 4.6 (-COO- $\left.\mathrm{CH}_{2}-\mathrm{CH}_{2}-\mathrm{O}-\mathrm{C}(\mathrm{O})-\mathrm{Ph}\right), 7.4$ - 8.1 (phenyl protons).

\section{Quaternization of branched poly(DMAEMA)s}

Methyl iodide $(0.6 \mathrm{~g}, 4.0 \mathrm{mmol}$, which corresponds to $c .2 .0$ molar excess compared to DMAEMA units) was added into a solution of $0.35 \mathrm{~g}$ of the copolymer (P5) in 20 $\mathrm{mL}$ acetone. The solution was stirred overnight at $25^{\circ} \mathrm{C}$. Then the quaternized product was separated by filtration and washed with acetone three times in order to remove the excess of methyl iodide. The resulting copolymer was dried in vacuum at room temperature to give a pale yellow powder $(0.64 \mathrm{~g})$.

${ }^{1} \mathrm{H}$ NMR $\left(\mathrm{D}_{2} \mathrm{O}\right): 0.6$ - $1.2\left(-\mathrm{CH}_{2}-\mathrm{C}\left(\mathrm{CH}_{3}\right)-\mathrm{COO}-\right), 1.7$ - $2.1\left(-\mathrm{CH}_{2}-\mathrm{C}\left(\mathrm{CH}_{3}\right)-\mathrm{COO}-\right), 3.0-$ $3.4\left(-\mathrm{N}\left(\mathrm{CH}_{3}\right)_{3}{ }^{+}{ }^{-}\right), 3.6$ - $4.0\left(-\mathrm{COO}^{-} \mathrm{CH}_{2}-\mathrm{CH}_{2}-\mathrm{N}\left(\mathrm{CH}_{3}\right)_{2}\right), 4.3$ - $4.6\left(-\mathrm{COO}-\mathrm{CH}_{2}-\mathrm{CH}_{2}-\right)$.

\section{Conclusions}

This paper provides a convenient synthetic method using commercially available monomers for the preparation of branched copolymers. Self-condensing oxyanionic copolymerization of HEMA and DMAEMA enable us to synthesize highly branched poly(DMAEMA)s. Molecular weight, composition and degree of polymerization can be 
adjusted by the comonomer ratio in the feed. Branched cationic polyelectrolytes were obtained after quaternization reaction of the branched poly(DMAEMA)s with methyl iodide. The obtained water-soluble branched cationic polyelectrolytes, containing the biomedical HEMA and DMAEMA units, may provide some possible applications in drug delivery systems.

Acknowledgement: The authors gratefully acknowledge financial support by the National Natural Science Foundation of China (No. 50233030 and 20274024) and the basic research foundation of Shanghai Science and Technique Committee.

[1] Jikei, M.; Kakimoto, M.; Prog. Polym. Sci. 2001, 26, 1233.

[2] Voit, B.; J. Polym. Sci., Part A: Polym. Chem. 2000, 38, 2505.

[3] Gao, C.; Yan, D.; Prog. Polym. Sci. 2004, 29, 183.

[4] Fréchet, J. M. J.; Henmi, M.; Gitsov, I.; Aoshima, S.; Leduc, MR.; Grubbs, R. B.; Science 1995, 269, 1080.

[5] Müller, A. H. E.; Yan, D.; Wulkow, M.; Macromolecules 1997, 30, 7015.

[6] Litvinenko, G. I.; Simon, P. F. W.; Müller, A. H. E.; Macromolecules 1999, 32, 2410.

[7] Litvinenko, G. I.; Simon, P. F. W.; Müller, A. H. E.; Macromolecules 2001, 34, 2418.

[8] Simon, P. F. W.; Müller, A. H. E.; Macromolecules 2001, 34, 6206.

[9] Simon, P. F. W.; Müller, A. H. E.; Pakula, T.; Macromolecules 2001, 34, 1677.

[10] Mori, H.; Seng, D. C.; Lechner, H.; Zhang, M. F.; Müller, A. H. E.; Macromolecules 2002, 35, 9270.

[11] Mori, H.; Walther, A.; Andre, X.; Lanzendorfer, M. G.; Müller, A. H. E.; Macromolecules 2004, 37, 2054.

[12] He, X. H.; Yan, D. Y.; Macromol. Rapid Commun. 2004, 25, 949.

[13] Jin, M.; Lu, R.; Bao, C. Y.; Xu, T. H.; Zhao, Y. Y.; Polymer 2004, 45, 1125.

[14] Hong, C. Y.; Pan, C. Y.; Polym. Int. 2002, 51, 785.

[15] Hong, C. Y.; Zou, Y. F.; Pan, C. Y.; Polym. Int. 2003, 52, 257.

[16] Ishizu, K.; Mori, A.; Polym. Int. 2001, 50, 906.

[17] Ishizu, K.; Shibuya, T.; Park, J. B.; Uchida, S.; Polym. Int. 2004, 53, 259.

[18] Ishizu, K.; Park, J. B.; Ohta, Y.; Shibuya, T.; J. Appl. Polym. Sci. 2003, 89, 2490.

[19] Lijima, M.; Nagasaki, Y.; Kato, M.; Kataoka, K.; Polymer 1997, 38, 1197.

[20] Nagasaki, Y.; Sato. Y.; Kato, M.; Macromol. Rapid Commun. 1997, 18, 827.

[21] Lascelles, S. F.; Malet, F.; Mayada, R.; Billingham, N. C.; Armes, S. P.; Macromolecules 1999, 32, 2462.

[22] Vamvakaki, M.; Billingham, N. C.; Armes, S. P.; Macromolecules 1999, 32, 2080.

[23] Sunder, A.; Hanselmann, R.; Frey H.; Mülhaupt, R.; Macromolecules 1999, 32, 4240. 
[24] Liu, M. J.; Vladimirov, N.; Fréchet, J. M. J.; Macromolecules 1999, 32, 6881.

[25] Smith, T. J.; Mathias, L. J.; Polymer 2002, 43, 7275.

[26] Jia, Z. F.; Yan, D. Y.; in preparation.

[27] Bohrisch, J.; Eisenbach, C. D.; Jaeger, W.; Mori, H.; Müller, A. H. E.; Rehahn, M.; Schaller, C.; Traser, S.; Wittmeyer, P.; Adv. Polym. Sci. 2004, 165, 1.

[28] Mori, H.; Müller, A. H. E.; Prog. Polym. Sci. 2003, 28, 1403.

[29] Baines, F. L.; Billingham, N. C.; Armes, S. P.; Macromolecules 1996, 29, 3416.

[30] Banez, M. V. D.; Robinson, K. L.; Bütün, V.; Armes, S. P.; Polymer 2001, 42, 29.

[31] Lee, W. F.; Huang, Y. L.; J. Appl. Polym. Sci. 2000, 77, 1769.

[32] Bütün, V.; Armes, S. P.; Billingham, N. C.; Macromolecules 2001, 34, 1148.

[33] Beers, K. L.; Boo, S.; Gaynor, S. G.; Matyjaszewski, K.; Macromolecules 1999, 32,5772 . 